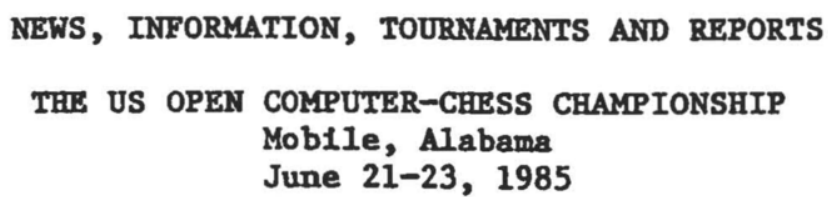

In Mobile, Alabama, the US Open Computer Chess Championship was held on June 21-23, 1985. It was the first computer-chess tournament to be sanctioned by the USCF. This was a large step forward on the road to acceptance of computer chess by the chess world. The sanctioning becomes even more gratifying when one calls to mind, that, three years ago, the USCF did not allow computers to play in their tournaments (cf. ICCA Journal, Vol. 6, No. 4, p. 15). It should be noted that this tournament is not one of the prestigious ACM tournaments, known as the NACCC, the (Open) North American Computer Chess Championship. The latter will be held soon again in Denver, Colorado (see Vol. 8, No. 2).

\title{
THE FIRST ROUNDS
}

Among the participants was Belle, the former world champion; she had also brought her little sister Bll (B eleven), a smaller yet older sister. Before the tournament, B11 impressed by playing well in speed chess against several chess-playing programmers. The little Belle, wrapped in a tiny hardware box, is quite an old chess program of Ken Thompson's. B11, a predecessor of Be1le, had never before recelved a rating and was registered in the tournament for callbrating purposes. Its tournament rating turned out to be lower than expected at $\frac{1}{2}$ out of 6 .

Big Belle already crash-landed in the first round against Mephisto Modular. In a drawn position at the 64th move, Belle went down and it was doubtful whether she would be able to recover in time. Ossi Weiner, one of Mephisto's designers, a strong chess-player himself, offered Belle a draw, as befits a gentleman. For Novag, on the other hand, the tournament started propitiously with four wins in the first round by its four machines, namely Novag X, Y, Super Con X, and Quattro X.

In the second round some commotion arose in connection with the game Fidelity Elite XC - Mephisto Exclusive S. Mephisto played the game very well. It had the advantage of a Knight and a Pawn. However, it lost on time on the 59 th move. With only one move to go, Mephisto did not make its 60th move in which it could even have captured Fidelity's last Rook; this would have resulted in an advantage of some 9 points. The fatal time trouble was not exactly due to the Mephisto machine. The operator was provided by the tournament committee; "this chap" had the habit of first writing down the moves Mephisto indicated on its built-in chess-board and only thereafter executing the moves and pushing the clock. Ossi Weiner was not at all happy with the course of things and he made a formal protest, which was denied.

\section{BUSINESS RULES}

In the third round, two Fidelity programs met on the board, both having $1 \frac{1}{2}$ out of 2, but one, Elite XC, being the company favourite. From the first moves, Avant Garde outplayed Elite XC. On the 36 th move, Avant Garde had a 
clear winning position, a Pawn up in a straight Bishop ending. Still, Fidelity's Avant Garde operator decided to resign. Most participants did not consider this correct. David Kittinger, for instance, said: 'To me, resigning in a won position goes beyond chess, no matter whether it is in the rules or not. You cannot throw a game. This is fixing a game, it is absurd.'

Some months later, Sid Samole, the President of Fidelity, when asked, admitted to having resigned on purpose. He said: 'it is not in the rules, therefore it is allowed.' The general feeling in this matter was that in this case the rules should be changed. In Mobile, the other programmers and operators felt no inclination to start a tug of war since 'businessmen always manage to prove that what they do is legal'.

All in all, after three rounds, Elite XC had $2 \frac{1}{2}$ out of 3 , but it could just as well have had $\frac{1}{2}$ out of 3 . In the last three rounds, it won all its games and so it won the tournament.

In the tournament table, it can be seen that many programs had been entered as unrated, a characterization usually indicating that the program had not yet played in an official tournament. All Fidelity programs so entered the tournament, although some of them had played rating tournaments, e.g., the ACM, with good results. Obviously, the special prize for unrated programs proved too much of a temptation and Fidelity indeed captured that prize by defeating Novag $\mathrm{Y}$ in the last round, in addition to the other trophies it obtained.

[The gist of the information above has been provided by David Kittinger; details have been confirmed independently. The Editor is glad to publish this report, but stresses that it rests on his own interpretation. The Editorial Board welcomes any form of technical discussion that might arise out of this report.]

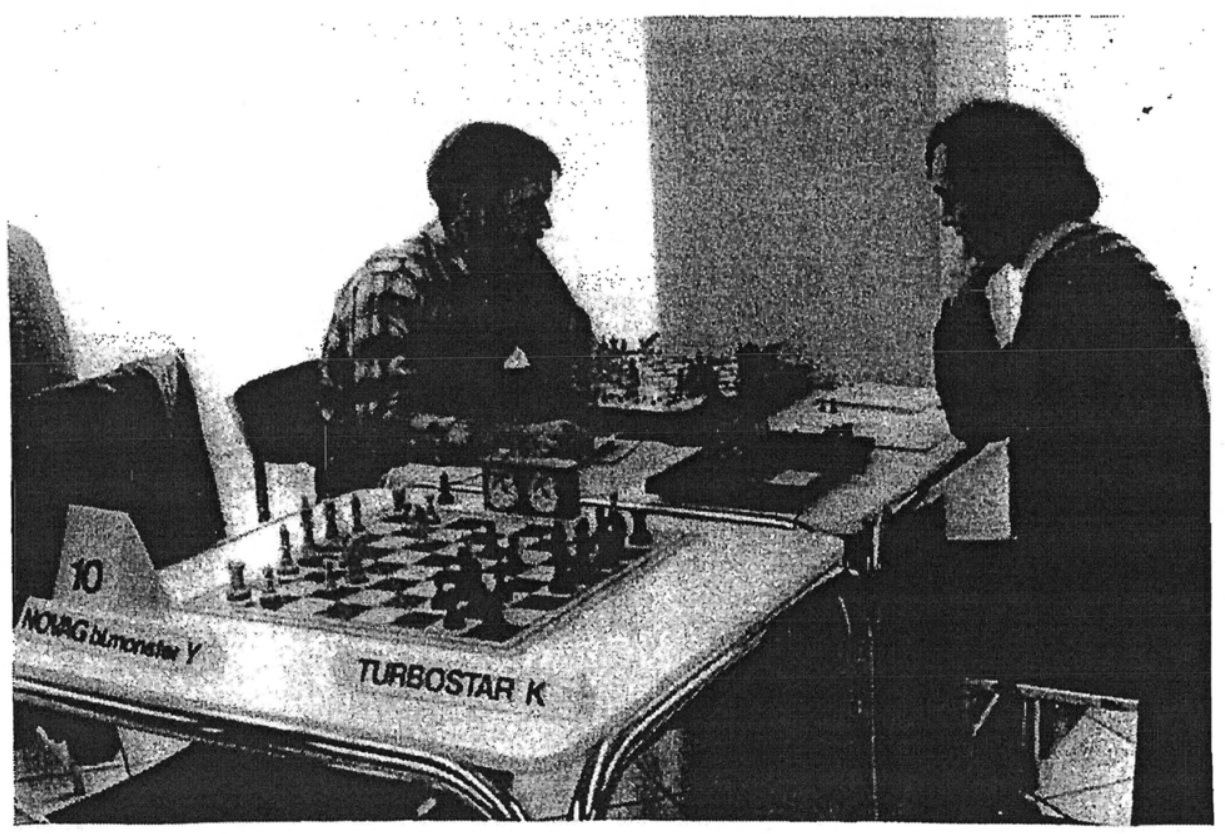

Photo by L. Lindner

IT TAKES THREE BOARDS ...

Kittinger at loggerheads with a striped operator? 